\title{
Een agogische vaardigheidstoets voor huisartsenpraktijkopleiders: beschrijving van een nieuw toetsinstrument
}

\author{
S. Schol
}

\section{Samenvatting}

In het kader van de opleiding van de praktijkopleiders van huisartsen in beroepsopleiding is naar analogie van het stationsexamen voor medische vaardigheden een toets ontwikkeld om de agogische vaardigheden van de praktijkopleiders te beoordelen. De toets bestaat uit zeven gesimuleerde leergesprekken van praktijkopleiders met een gestandaardiseerde huisarts in beroepsopleiding. De eerste ervaringen zijn gunstig. De reacties van deelnemers en observatoren zijn positief. De toets lijkt waardevolle informatie te kunnen verschaffen voor praktijkopleiders en opleiding en biedt een nieuw perspectief in de verdere professionalisering van de huisartsenopleiding. Onderzoek naar de betrouwbaarheid, validiteit en bruikbaarheid is gaande. (Schol S. Een agogische vaardigheidstoets voor huisartsenpraktijkopleiders: beschrijving van een nieuw toetsinstrument. Tijdschrift voor Medisch Onderwijs 2000;19(5): 179-186.)

\section{Inleiding}

De huisartsopleiding in Vlaanderen duurt drie jaar. Het eerst jaar hiervan valt binnen de zeven jaar durende medische basisopleiding. In het zevende jaar van het basiscurriculum volgen de studenten reeds onderwijs in de richting van hun vervolgopleiding. Deze richtingen zijn: medisch specialist, sociale geneeskunde, wetenschappelijk onderzoek en huisartsgeneeskunde. Het eerste jaar van de huisartsopleiding wordt lokaal georganiseerd door de huisartsencentra van de vier Vlaamse medische faculteiten (Leuven, Gent, Antwerpen en Brussel). Het tweede en derde postacademische jaar van de beroepsopleiding wordt georganiseerd door het Interuniversitair Centrum voor de Huisartsenopleiding (ICHO). Naast deelname aan verschillende gestructureerde onderwijsactiviteiten moet de huisarts in beroepsopleiding gedurende deze twee jaar de huisartsgeneeskunde voltijds als stage uitoefenen. Van de stagebiedende huisarts, de huisartsenpraktijkopleider of kortweg praktijkopleider, wordt meer verwacht dan alleen een stagewerkplek bie- den. Hij moet ook opleiden. Het ICHO heeft een training opgezet om de praktijkopleiders op deze taak voor te bereiden. ${ }^{1}$ Om de vorderingen op het gebied van agogische vaardigheden vast te stellen en tussentijds informatie te verkrijgen over het verloop van het leerproces bij de praktijkopleiders is een diagnostisch stationsexamen ontwikkeld: de Agogische Vaardigheidstoets. Over een dergelijke vaardigheidstoets voor docenten is, voor zover wij weten, niet eerder gepubliceerd. In dit artikel worden de ontwikkeling en uitvoering van deze toets in detail beschreven. Later zal verslag gedaan worden van onderzoek naar de validiteit, betrouwbaarheid en bruikbaarheid van het instrument.

\section{De toetsinhoud}

Het ICHO legt de nadruk op drie begeleidingsactiviteiten in de huisartsenopleidingspraktijk: 1) de dagelijkse patiëntenbespreking en het werkoverleg; 2) een wekelijkse thema- of casusbespreking; en 3) het maandelijks opstellen en evalueren van de leeragenda. ${ }^{2}$ Van Geldorp onder- 
scheidt 21 verschillende vormen van leergesprekken van de stagebegeleider met de huisarts in opleiding. ${ }^{3}$ Deze twee invalshoeken zijn als leidraad gebruikt bij het selecteren van zeven opleidingsactiviteiten voor opname in de Agogische Vaardigheidstoets: een leeragenda opstellen, een adviesgesprek voeren, een patiëntenbespreking, een besliskundige casusbespreking, een feedbackgesprek, het demonstreren van een vaardigheid en een tussentijds evaluatiegesprek. De toets meet dus niet de beheersing van medische vaardigheden. Omdat de beheersing hiervan de toetsresultaten kan beïnvloeden, werd besloten om de medische onderwerpen vooraf aan de deelnemers bekend te maken.

\section{Het toetsinstrument}

Voor het meten van onderwijsresultaten bestaat een groot aantal observatie-instrumenten. Deze zijn echter meestal niet gericht op het toetsen van agogische vaardigheden. Onze toets moet informatie geven over de competentie van de praktijkopleider betreffende agogische vaardigheden, zoals het opstellen van een leeragenda of het uitdiepen van een casus. Naar analogie van het stationsexamen voor medische vaardigheden, het Objective Structured Clinical Examination, hebben we een stationsexamen ontwikkeld voor bovengenoemde agogische vaardigheden. ${ }^{4} 5$ In stationsexamens in de geneeskundeopleidingen worden vaardigheden vaak getoetst door middel van contacten met gestandaardiseerde patiënten. De stations van de Agogische Vaardigheidstoets bestaan alle uit contacten met gestandaardiseerde huisartsen in opleiding. De vaardigheden van de praktijkopleiders werden beoordeeld door de gestandaardiseerde huisartsen in opleiding en door twee observatoren. Voor elk van de zeven opleidingsactiviteiten werd een zo nauwkeurig en realistisch mogelijk scenario ontwikkeld om de betreffende vaardigheid te kunnen toetsen. Deze scenario's omvatten een beschrijving van de betreffende opleidingsactiviteit, de verantwoording en de leerdoelen, de instructies en rolomschrijving voor de gestandaardiseerde huisarts in beroepsopleiding, een opdrachtomschrijving voor de deelnemers, de scoreformulieren instructies voor de observatoren, algemene richtlijnen en een tijdschema. Voor de zeven opleidingsactiviteiten werden zes stations ingericht van elk twaalf minuten. In één van de zes stations werden twee vaardigheden getoetst, waarvoor respectievelijk acht en vier minuten beschikbaar waren. De overige stations toetsten elk één vaardigheid.

\section{Scoreformulieren}

Voor elk station werd een scoreformulier ontwikkeld door de betreffende opleidingsactiviteit te vertalen in operationeel gedrag (de criteria). ${ }^{6}$ Vervolgens werden voor elk station kwaliteitsindicatoren ontwikkeld op basis van een aantal onderwijskundige modellen, de principes voor volwasseneneducatie en aanwijzingen vanuit het ICHO. ${ }^{7-10}$ De ontwerpversies van de scoreformulieren werden meerdere malen voorgelegd aan de stafmedewerkers van het ICHO. De scoreformulieren werden uitgeprobeerd met behulp van bandopnames van leergesprekken, die beschikbaar gesteld werden door enkele gemotiveerde praktijkopleiders. Alle scoreformulieren bestonden uit drie à vijf hoofditems te scoren op een vijfpuntsschaal en één tot zeven deelitems te scoren op een ja-nee-schaal. Er werden vijf procesitems toegevoegd en een item 'globale indruk van het gehele station', allebei te scoren op een vijfpuntsschaal (figuur 1). 
Figuur 1. Voorbeeld scoreformulier adviesgesprek van praktijkopleider met gestandaardiseerde huisarts in beroepsopleiding.

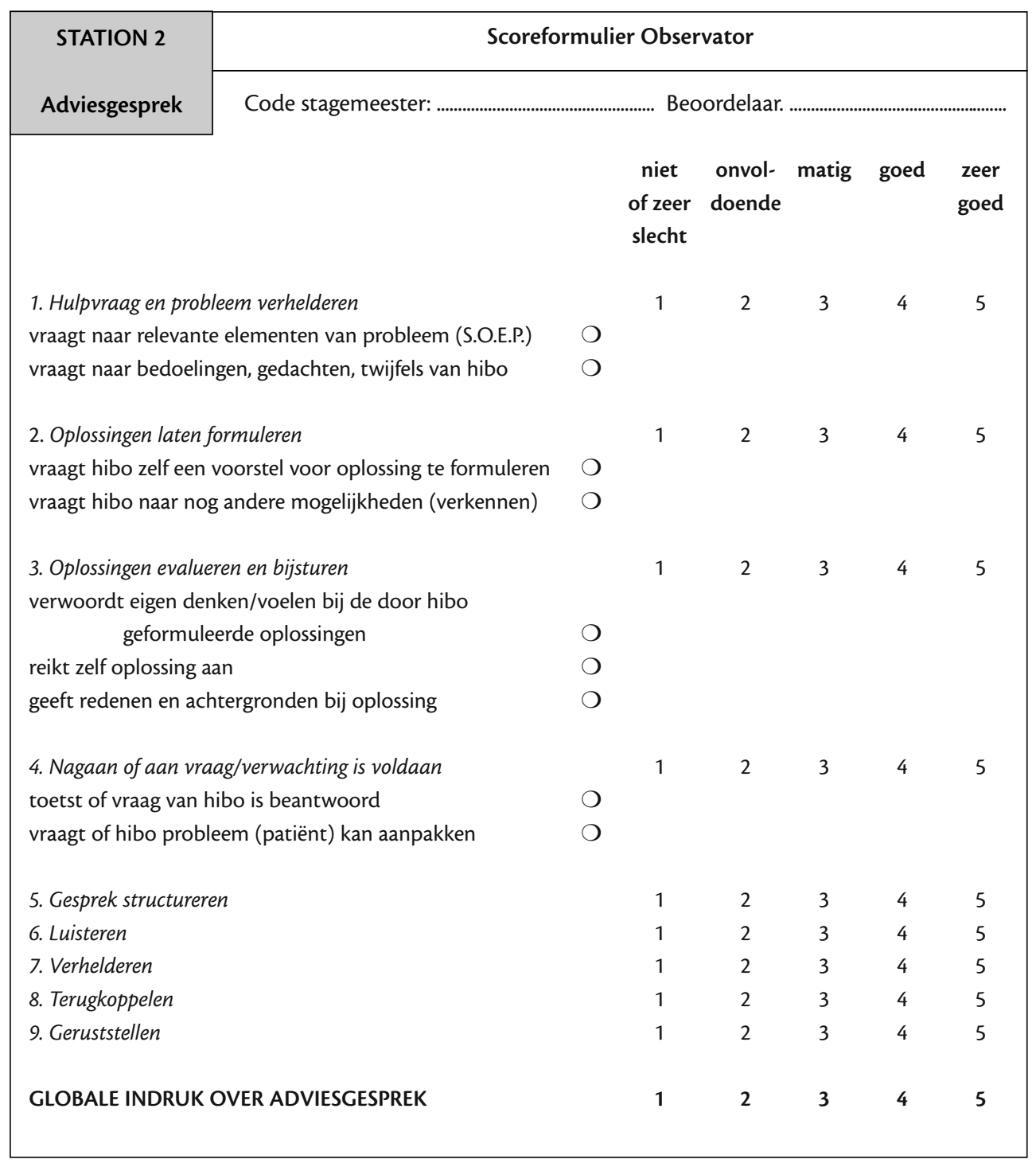

\section{Gestandaardiseerde huisartsen in} beroepsopleiding

Elk station is een gesimuleerde opleidingssituatie. Omdat alle deelnemers een vergelijkbare toets moeten kunnen afleggen, is in navolging van de gestandaardiseerde patiënt bij onderwijs en onder- zoek, de gestandaardiseerde student ingevoerd. 1112 Voor de rol van gestandaardiseerde huisarts in opleiding in de zes stations werden in totaal twaalf huisartsen in beroepsopleiding getraind. Er was dus één reserve voor elk station. $\mathrm{Na}$ het instuderen van hun rol, oefenden deze 
gestandaardiseerde huisartsen in beroepsopleiding hun rol in duo's in rollenspelen met verschillende opleiders. Op basis van de bevindingen tijdens deze oefeningen werden de rollen bijgewerkt. De gestandaardiseerde huisartsen in beroepsopleiding waren tevens beoordelaar: zij scoorden op een beoordelingsformulier elf items op een vijfpuntsschaal. Deze elf items waren gericht op aspecten als contact met de praktijkopleider, didactische instelling, structuur van het gesprek en een algemene beoordeling.

\section{Observatoren}

Per station werden twee observatoren ingezet om de interobservatorvariatie na te gaan. Tevens werd elk station op video opgenomen om het station eventueel op een later tijdstip opnieuw te kunnen scoren. Een deel van de observatoren werd gerekruteerd uit de medewerkers (stafleden en coördinatoren van de huisartsopleiding) van het ICHO. Zij kregen de scoringsformulieren met instructies vooraf toegestuurd. Voor vragen en opmerkingen konden zij via telefoon of e-mail contact opnemen. De andere observatoren waren sociale wetenschappers (medewerkers en studenten psychologie en opvoedkunde, en een germaniste) die vertrouwd waren met de agogische principes maar niet verbonden waren aan het centrum. Ook zij kregen de scoringsformulieren en instructies vooraf toegestuurd. Voor hen werd een aparte bijeenkomst belegd voor uitleg over de structuur en de werking van de organisatie - het kader waarbinnen zij hun opdracht dienden uit te voeren - en voor toelichting bij het project.

\section{Beschrijving van de verschillende stations} Station 1 -een leeragenda opstellen: In dit station werd de praktijkopleider gevraagd om in overleg met de huisarts in beroeps- opleiding een leeragenda op te stellen. Het doel was dat de praktijkopleider hulp bood aan de huisarts in opleiding om leerdoelen te concretiseren, blinde vlekken op te sporen, hulpmiddelen te zoeken en de vorderingen te evalueren. Het gesprek moest uitmonden in een keuze van de belangrijkste leerdoelen, een concreet werk- en leerplan en afspraken over taakverdeling en evaluatie. De huisarts in beroepsopleiding wilde meer weten over het gynaecologisch onderzoek.

Station 2 (dubbelstation) - een adviesgesprek voeren: Een huisarts in beroepsopleiding moet op elk moment met een acute vraag bij de praktijkopleider terecht kunnen. Meestal is hiervoor weinig tijd beschikbaar, waardoor de praktijkopleider veelal geneigd is om zelf direct de oplossing te formuleren. Belangrijk is echter dat de huisarts in beroepsopleiding eerst via een kort leergesprek gestimuleerd wordt om het probleem zelf te analyseren en een oplossing voor te stellen. Pas als dat niet lukt, kan de opleider eigen oplossingen aanreiken. De gestandaardiseerde huisarts in beroepsopleiding consulteerde de praktijkopleider met het probleem 'patiënt Jan Meesen had thuis vooraan in zijn slip bloed gezien. Ik heb zijn urine onderzocht en zie geen bloed. Wat moet ik nu verder doen?'

Station 3 (dubbelstation) - een patiëntenbespreking: Het (dagelijks) kort verslag van de patiëntencontacten vormt een uitstekende gelegenheid om problemen of vragen van de huisarts in beroepsopleiding te herkennen en deze te helpen concrete leerdoelen te formuleren. ${ }^{13} 14 \mathrm{De}$ gestandaardiseerde huisarts in beroepsopleiding rapporteerde over vier patiëntencontacten: 1) een vierjarig jongetje met otitis media; 2) een dame van 30 jaar met acute cystitis; 3 ) een 66-jarige man met 
bronchiale infectie... of misschien toch een hartdecompensatie; 4) een 56-jarige dame met ontregelde diabetes ... of misschien ook wel een beginnende urineweginfectie. De praktijkopleider diende de problemen/vragen van de huisarts in beroepsopleiding te herkennen en te agenderen voor een volgend opleidingsmoment.

Station 4 - een besliskundige casusbespreking: In een casusbespreking wordt één patiënt of probleem grondig uitgediept. Op deze manier kan de huisarts in beroepsopleiding leren om theoretische kennis toe te passen op echte problemen en kan een betere integratie van het geleerde plaatsvinden. In dit station presenteerde de gestandaardiseerde huisarts in beroepsopleiding het probleem thoracale pijn. Ze stelde bij mevrouw Peeters (72 jaar, klacht: hoesten) de diagnose 'thoracale wandpijn en faryngotracheïtis'. Achteraf twijfelde ze. Was dit toch geen angina pectoris? Waren haar diagnostische overwegingen, zelfs met de mogelijkheid angina pectoris, wel volledig genoeg?

Station 5 - een feedbackgesprek: Feedback is bedoeld om ruimte voor verandering te bieden. Om dit te realiseren dient de huisarts in beroepsopleiding de kans te krijgen om eerst zelf verslag te doen van ervaringen en suggesties voor verbetering te formuleren. Goede feedback omvat een evenwichtige beschrijving van positieve en te verbeteren punten samen met suggesties voor verbetering of alternatieven voor het toekomstig handelen. In dit station was het feedbackgesprek met de huisarts in beroepsopleiding gericht op de technische uitvoering van een cervixuitstrijkje. De praktijkopleider kreeg eerst een video-opname (vier minuten) te zien van de huisarts in beroepsopleiding die een uitstrijkje maakt op een fantoom van het vrouwelijk bekken. Daarna begint het feedbackgesprek. De video-opname werd gekozen om te vermijden dat de praktijkopleider reeds zou ingrijpen en bijsturen tijdens de uitvoering van het onderzoek. Het gebruik van een fantoom verplichtte de praktijkopleider zich te richten op de technische uitvoering van het uitstrijkje en niet op het contact en de communicatie met de patiënt.

Station 6 - een demonstratie: Onder demonstreren wordt verstaan 'het expliciteren en het tonen van een onderzoeksvaardigheid, een handeling, het gebruik van een instrument of een gesprekstechniek'. Hierbij moet aandacht zijn voor aspecten als voordoen, uitleggen, observeren, nota nemen en bespreken. De praktijkopleider beschikte over een model waarop hij aan de huisarts in beroepsopleiding de techniek van de kniepunctie kon demonstreren.

Station 7 - een tussentijds evaluatiegesprek: De maandelijkse evaluatiegesprekken dienen gericht te zijn op de ontwikkeling van de huisarts in beroepsopleiding. Praktijkopleider en huisarts in beroepsopleiding blikken terug op de afgelopen werk- en leerperiode en geven hun eigen opvattingen en oordelen weer. Uitgaande van een vooraf gemaakte leeragenda, worden de gebeurtenissen besproken. Uit de analyses en evaluaties van de voorbije periode, kunnen conclusies getrokken worden. De praktijkopleider evalueerde 'de betekenis van niet-medicamenteuze behandelingsstrategieën bij hypertensie' en 'het in overeenstemming brengen van het voorschrijfgedrag met de NHG-standaard ongecompliceerde urineweginfecties bij de vrouw'. 


\section{De toetsuitvoering}

\section{Deelnemers}

Uit de lijst van praktijkopleiders die minstens twee jaar in opleiding waren $(n=209)$, werd een aselecte gestratificeerde steekproef van 40 kandidaten (acht kandidaten uit elk van de vijf provincies) getrokken. Ze kregen een brief met uitleg over de eerste experimentele Agogische Vaardigheidstoets en de vraag om hieraan deel te nemen. Een week later werd telefonisch contact gezocht om deelname of weigering vast te stellen. Van de oorspronkelijk geselecteerde 40 kandidaten haakten er in de loop van de rekrutering 21 af. Na elke weigering werd at random een nieuwe kandidaat uit de betreffende lijst geselecteerd, waarbij dan dezelfde aanpak gevolgd werd. Deze procedure werd herhaald totdat 36 praktijkopleiders hun deelname bevestigd hadden. Vanwege onverwachte ziekte viel één deelnemer uit, zodat uiteindelijk 35 praktijkopleiders aan de toets deelnamen.

\section{Afname}

De Agogische Vaardigheidstoets vond plaats in lokalen van het vroegere universitaire ziekenhuis van Leuven, waar kamers zijn ingericht voor vaardigheidstrainingen voor medisch studenten. De toets werd gepland op een tijdstip dat de praktijkopleiders zich zo makkelijk mogelijk konden vrijmaken. Dit bleek de donderdagnamiddag te zijn. Tevens werd de toetstijd zo beperkt mogelijk gehouden. Er werden twee toetsmomenten georganiseerd. Per namiddag doorliepen drie groepen van zes praktijkopleiders de stationsproef. Elke groep werd uitgenodigd om een kwartier voor aanvang aanwezig te zijn. In deze vijftien minuten kregen zij informatie over hun opdracht en over het verloop van de toets. We vroegen hun na elk station een vragenlijst in te vullen over onder andere beschikbare tijd, relevantie, moeilijkheid en duidelijkheid van de opdracht. In elk lokaal bleef men twaalf minuten. Na tien minuten ging er een waarschuwingssignaal; na twaalf minuten ging het doorschuifsignaal. Het leergesprek werd dan onmiddellijk stopgezet en de observatoren, de gestandaardiseerde huisarts in beroepsopleiding en de deelnemer vulden hun vragenlijst in (ongeveer vijftien seconden), waarna de deelnemers naar een volgend station gingen. Na 75 minuten was de gehele toets doorlopen en kon stoom afgeblazen worden bij één van de medewerkers van de toetsorganisatie.

Tijdens de toetsafname werd ook een externe observator ingeschakeld, die de gehele gang van zaken observeerde en de participanten en medewerkers om hun indrukken vroeg.

\section{Resultaten}

\section{Feedback aan de deelnemers}

Aan de deelnemers was vooraf verteld dat zij enkele weken na afloop van de toets de resultaten en feedback over hun handelen zouden krijgen. Er was tijdens de toets onvoldoende tijd beschikbaar om onmiddellijk onderwijskundig verantwoorde feedback te geven. Elke deelnemer kreeg uiteindelijk een uitvoerig individueel verslag over het eigen handelen thuisgestuurd. In dit verslag werden per station en voor de gehele toets de volgende gegevens gerapporteerd: de individuele score, de gemiddelde score voor alle deelnemers en een aantal parameters zoals standaardafwijking, mediaan, modus en spreiding. Op basis van de individuele observatieformulieren werden voor iedere deelnemer de positieve en te verbeteren punten beschreven. Elke kandidaat kreeg eveneens de beoordelingen van de gestandaardiseerde huisartsen in beroepsopleiding gerapporteerd. 


\section{Eerste oriënterende evaluatie}

Uit het verslag van de externe observator bleek dat over het algemeen de stations erg realistisch en relevant werden gevonden, de huisartsen in beroepsopleiding hun rollen goed speelden en de organisatie van de toets goed was. De praktijkopleiders vonden het geen probleem dat zij de huisartsen in beroepsopleiding niet kenden. Het feit dat het om onbekende patiënten ging, werd wel als moeilijk ervaren. Opvallend was dat de praktijkopleiders de gebruikte terminologie in de opdrachten niet steeds bleken te kennen. De tijdsbesteding voor de toets zelf vonden de deelnemers acceptabel. Wel werd aangegeven dat de toets bij voorkeur zo dicht mogelijk bij de praktijk dient plaats te vinden (niet meer dan dertig minuten reistijd). De stafleden van het ICHO vonden hun participatie als observator zeer leerzaam. Ze ontdekten op welke deelterreinen in de opleiding van de praktijkopleiders bijsturing en verbetering nodig was.

Uit de respons op de vragenlijsten bleek dat de tijd voor het dubbelstation 'adviesgesprek en patiëntenbespreking' te beperkt was. Ten aanzien van de relevantie scoorden alle stations goed tot zeer goed. Hetzelfde gold voor het realiteitskarakter ervan. De opdracht van het station 'tussentijds evaluatiegesprek' werd als onvoldoende duidelijk ervaren. Alle stations werden matig moeilijk tot gemakkelijk gevonden. Eén praktijkopleider uitte een klacht over tijdverlies door de uitzonderlijk lange reistijd.

\section{Beschouwing}

Het is mogelijk gebleken om naar analogie van het stationsexamen een toets op te zetten waarmee op realistische en relevante wijze de agogische vaardigheden van huisartsopleiders beoordeeld kunnen worden. De eerste ervaringen zijn gunstig. Zowel praktijkopleiders als begeleiders van de opleiding van praktijkopleiders reageerden positief. Het ziet ernaar uit dat een dergelijke toets waardevolle informatie kan verschaffen voor individuele feedback aan praktijkopleiders, maar ook voor bijstelling van de scholing van praktijkopleiders. Dat komt ten goede aan de kwaliteit van de huisartsenopleiding.

Voor zover ons bekend is deze toets ter beoordeling van de didactische kwaliteiten van opleiders in het medisch basis- en vervolgonderwijs uniek. Dit is verwonderlijk. Opleiden en onderwijzen vereist immers specifieke vaardigheden waarover docenten meestal niet vanzelf beschikken Docentenprofessionalisering is derhalve nodig en door middel van toetsing kan vastgesteld worden in hoeverre doelen bereikt worden. Wellicht vormt de investering die nodig is om zorgvuldig te toetsen een te grote belemmering. Ook in ons geval was die aanzienlijk. Van meet af aan is bijzonder veel zorg besteed aan het vertalen van de agogische vaardigheden in zo concreet mogelijke gedragingen. Ook de ontwikkeling van realistische scenario's waarin deze gedragingen gedemonstreerd konden worden, is zorgvuldig ter hand genomen. Dat kost relatief veel tijd en mankracht, maar dit is nodig met het oog op de kwaliteit van de toets. Daar staat tegenover dat het eenmalige investeringen betreft. Is het instrument eenmaal goed en wel ontwikkeld dan beperken de kosten zich tot de afname en rapportage. Die zijn overigens ook niet gering als alleen al aan de inzet van observatoren en gestandaardiseerde huisartsen in opleiding gedacht wordt. Is het instrument eenmaal goed uitgetest, dan is wellicht geen tweede observator meer nodig. Al met al is het van groot belang dat de kwaliteit van deze eerste experimentele Agogische Vaardigheidstoets voor praktijkopleiders goed vastgesteld wordt. Betrouwbaarheid, validiteit en bruikbaarheid moeten zorg- 
vuldig onderzocht worden. Dit onderzoek is gaande en zal binnenkort gerapporteerd worden. We menen dat de eerste stap gezet is in de ontwikkeling van een nieuw instrument dat van groot belang kan zijn bij de verdere professionalisering van het onderwijs aan toekomstige huisartsen.

\section{Literatuur}

1. Stubbe C. Stappenplan 'naar academische opleidingspraktijken' [intern werkdocument]. Leuven: Interuniversitair Centrum voor Huisartsenopleiding; 1998.

2. Leroy DR, Derese A. Handboek voor de stagemeester die een huisarts in beroepsopleiding opleidt. ICHO-uitgaven. Leuven: Interuniversitair Centrum voor Huisartsenopleiding; september 1995.

3. Geldorp G van, Amerongen HL van, Haan M de. Opleiden en leren in de huisartspraktijk. Een leidraad voor opleiders en huisartsen in opleiding. Utrecht: Wetenschappelijke Uitgeverij Bunge; 1993.

4. Walker R. Use of the objective structured clinical examination for assessment of vocational trainees for general practice. J R Coll Gen Pract 1987;37:123-4.

5. Tan LHC, Foolen CHGM, Geldorp G van. Het toetsen van vaardigheden in de beroepsopleiding tot huisarts. Medisch Contact 1990;19:618-20.

6. Schol S. Doelstellingen agogische vaardigheden voor de opleiding van praktijkopleiders [intern werkdocument]. Leuven: Interuniversitair Centrum voor Huisartsenopleiding; 1998.
7. Dochy FJ, Luijk SJ van. Handboek vaardigheidsonderwijs. Lisse: Swets \& Zeitlinger; 1987.

8. Knowles MS. Andragogy in action. San Francisco California: Jossey-Bass Publishers; 1984.

9. Knowles MS. The adult learner: a neglected species. Houston: Gulf; 1990.

10. Derese A, Leroy DR. Betrachtingen ten aanzien van stagemeesters die een huisarts in beroepsopleiding opleiden en ten aanzien van hun praktijk [discussienota]. Leuven: Interuniversitair Centrum voor Huisartsenopleiding; 1997.

11. Beullens J, Rethans JJ, Goedhuys J, Buntinx F. The use of standardised patients in research in general practice. Family Practice 1997;14:58-62.

12. Lesky LG, Wilkerson L. Using standardized students to teach a learner-centered approach to ambulatory precepting. Acad Med 1994;69:955-7.

13. Meyboom WA, Metsemaekers JFM, Hofstra ML, Beusmans GHMI. NHG-Standaard Medische Verslaglegging. Huisarts Wet 1990;33:114-7.

14. Werf GT van der. Probleemlijst, SOEP en ICPC Huisarts Wet 1996;39:265-70.

Bijzondere dank aan dr. P.M. Boendermaker, Afdeling Huisartsopleiding, Disciplinegroep Huisartsgeneeskunde, Rijksuniversiteit Groningen, voor de medewerking als extern observator aan de Agogische Vaardigheidstoets.

De auteurs:

S. Schol is agoog en verbonden aan het Interuniversitair Centrum voor Huisartsenopleiding, Leuven.

Correspondentieadres:

S. Schol, I.C.H.O., Kapucijnenvoer 33, 3000 Leuven, België, tel: 016/44 8771.

\section{Summary}

A teaching skills assessment test (TSAT) has been developed in order to determine the individual competence of GPs acting as preceptors in the Flemish general practice vocational training programme. In seven stations the examinees $(n=35)$ have to demonstrate adequate precepting skills in encounters with simulated GPs in training. The first experiences are encouraging. Both examinees and observers responded favourably to the test. The TSAT appears to provide useful feedback to GP preceptors in training. The reliability, validity and feasibility of the TSAT are being studied and will be reported in due course. (Schol S. Teaching skills of GP preceptors: a description of a new assessment tool. Dutch Journal of Medical Education 2000;19(5): 179-186.) 